\title{
BMJ Open Clinical Nursing Introduction Program for new graduate nurses in Sweden: study protocol for a prospective longitudinal cohort study
}

\author{
Anita Johansson (D) , ${ }^{1}$ Mia Berglund, ${ }^{2}$ Anna Kjellsdotter ${ }^{1,2}$
}

To cite: Johansson A, Berglund M, Kjellsdotter A. Clinical Nursing Introduction Program for new graduate nurses in Sweden: study protocol for a prospective longitudinal cohort study. BMJ Open 2021;11:e042385. doi:10.1136/ bmjopen-2020-042385

- Prepublication history is published online only. To view please visit the journal online (http://dx.doi.org/10.1136/ bmjopen-2020-042385).

Received 05 July 2020 Revised 07 January 2021 Accepted 13 January 2021

D Check for updates

(C) Author(s) (or their employer(s)) 2021. Re-use permitted under CC BY-NC. No commercial re-use. See rights and permissions. Published by BMJ.

${ }^{1}$ Research and Development Centre, Skaraborg Hospital, Skovde, Vastra Gotaland,

Sweden

${ }^{2}$ School of Health Sciences, Skövde University, Skövde, Sweden

\section{Correspondence to} Anita Johansson; anita.ulla.johansson@vgregion. se

\section{ABSTRACT}

Introduction High levels of nursing turnover represent a problem for healthcare organisations and patient safety. Experiences during the first years in the nursing profession have a significant impact on nurses' future decisions concerning their careers. Nurses at the start of their professional career need to practise their hands-on skills as well as their theoretical knowledge. In addition, new graduate nurses need regular support and opportunities to reflect on experiences in their new profession. The aim of the present study is to describe the Clinical Nursing Introduction Program (CNIP) and present a study design in which the programme is used to support new graduate nurses' transition into the nursing profession.

Method and analysis The present study examines the CNIP at a general hospital in southwest Sweden, which lasts for 14 months. The programme has a unique profile based on a person-centred approach and consists of five components: employment and organisation, a compulsory introduction week, two placements in different clinical settings, education days and process-oriented nursing supervision. The present study presents a protocol for a prospective longitudinal cohort study, using qualitative and quantitative methods in the collection and analysis of data. Measurements will include data collection between 2019 and 2023 when the nurses start the CNIP (baseline) and then after 1 and 2 years.

Ethics and dissemination This study has been approved by the Regional Ethical Review Board in Gothenburg (Dnr 1056-18). Study findings will be presented at national and international conferences and published in peer-reviewed journals.

Trial registration number 273573 (https://www. researchweb.org/is/vgr).

\section{INTRODUCTION}

In the transition from student to registered nurse, new graduate nurses experience significant challenges. ${ }^{1-4}$ Increased workloads with inadequate staffing, multiple role demands and workplace incivility are noted stressors. ${ }^{45}$ New graduate nurses are expected to be experts in caring science and to perform medical and technical tasks that often give them less time to interact with and care for
Strengths and limitations of this study

- A major strength in this prospective longitudinal cohort study design is the use of both qualitative and quantitative methodology in the collection of data.

- Another strength is that validated and reliabilitytested questionnaires will be used at baseline and after 1 and 2 years.

- The results of this study may show that the unique Clinical Nursing Introduction Program with its core components creates conditions for retaining the new graduate nurses.

- The potential limitation of this study design includes the lack of an adequate full-term comparison group.

their patients. ${ }^{3}$ Duchscher ${ }^{6}$ describes nurses' fear of not being accepted by their colleagues; furthermore, they have no clear understanding of what is expected of them. Failure to thrive in the demanding clinical environment, ${ }^{7}$ workplace incivility ${ }^{8}$ and high levels of burnout ${ }^{9}$ have been identified as predictors of low job satisfaction and contribute to the high levels of turnover connected with the first years of new graduate nurse employment. Nursing turnover is described as a concept that encompasses everything from leaving a position or transferring within a healthcare organisation (internal turnover) to leaving the profession (external turnover). ${ }^{10}$ In a longitudinal study, Rudman $e t a l^{\dagger}$ found that every fifth nurse strongly intended to leave the profession after 5 years. These high turnover rates impact the quality of care, patient safety and organisational reputation. ${ }^{11}$

In the last decade, hospital care has become more specialised, while student nurses' time for practise in hospital care has decreased. Gaps between undergraduate education and clinical practice have been identified as a common problem in nursing. ${ }^{12}$ The learning process, which never stops, changes with time and is dependent on external and inner 
factors and the need to acquire new knowledge. At the beginning of their career, a new nurse uses rules, principles and written routines in caring. After some years, the nurse, who is now more of an expert than a beginner, uses previous experience, knowledge and principles to understand a caring situation and acts according to the assessed situation. ${ }^{13}$ Collaboration between nursing schools, clinical partners and healthcare facilities is essential to determine the best learner-centred methods for preparing new graduate nurses for practice. ${ }^{2}$ Nurse leaders should work to create unit cultures that foster learning by encouraging new graduate nurses to ask questions and seek feedback without fear of criticism or incivility. ${ }^{14}$

Opportunities to share experiences with colleagues and the presence of support from supervisors in clinical settings are necessary to keep nurses motivated to remain in the profession. ${ }^{15}$ New graduate nurses reported less stress when participating in clinical group supervision, including support, development and shared reflection. ${ }^{16}$ Extended transition benefits for new graduate nurses have a lasting effect over time and impact key dimensions of care delivery, enhance workforce integration and reduce turnover. ${ }^{17}$

A worldwide review of current literature supports nurses' transition from undergraduates to independent health professionals through transition programmes. ${ }^{18-20}$ These transition programmes have varied content and differing lengths from 6 weeks to 12 months. The overall goals of the different programmes are to reduce stress and develop professional competence. ${ }^{18}$ Retention of new graduate nurses within the profession can be supported by clinical education, experienced nurses' support and seminars in transition programmes. ${ }^{19} 20$ In addition, Aggar et $a l^{19}$ emphasise the importance of supervision and educational support, overseen by a transition facilitator.

In Sweden today, the corresponding introduction programme for new graduate nurses, with some variation in extent, design and content, is available in more than half of the country's 21 regions. One aspect that is common to the introduction programmes is that they are expected to offer the opportunity for further development of clinical skills and create a safe transition between education and employment, which in turn is expected to improve the conditions for the new graduate nurses to stay in the profession. ${ }^{21}$

Research has shown the importance of establishing routines that initiate, integrate and safeguard personcentred care (PCC) in daily clinical practice. PCC is an approach that views the patient as a person who should not be reduced to their disease alone. The core component of PCC is the partnership between patient, relatives and care provider through the patient's narrative, which places the person's views about their life situation and condition at the centre of care. ${ }^{22}$ Further, this approach is also applicable between coworkers; it reflects the potential impact of staff relationships and team effectiveness on creating a therapeutic environment. ${ }^{23}$ PCG is an ethical guide to practical actions as a human being and a professional. ${ }^{24}$

\section{Theoretical framework}

The theoretical framework for the transition process of new graduate nurses to professional development is Meleis' transition theory, which deals with changes, transitions and interventions that affect people's lives. ${ }^{25} 26$ The nursing profession is an ongoing and cyclical process of learning, reflecting and accepting. This makes the first transition into becoming a nurse extremely important for continual personal and professional development. To understand transition, it is important to identify the factors that facilitate or stand in the way of a healthy transition. A transition of any kind can be seen as a universal human trait that involves undergoing a change in wellbeing and being willing to accept a process of change currently underway. Expectations of the new role also play a part in transitions. The time span for transitions is not a limited property; transition is an ongoing process and variability over time affects the outcome. ${ }^{25}$

In summary, previous research shows that new graduate nurses are expected to act beyond their actual capacity, and the gap between theoretical knowledge and practical experience during their education is too wide. Experiences during the first years in the nursing profession have a significant impact on nurses' future decisions concerning their career. Continual mentoring, opportunities to reflect on experiences and support from colleagues in their everyday work is extremely important for the reduction of feelings of stress and inadequacy. Nurses' turnover rates are high, and reasons for leaving can be related to stress, the unexpected expectations on one's work readiness and difficulties in translating theoretical knowledge to clinical practice. Individual and organisational factors that might contribute to the new graduate nurses' experiences of stress have rarely been explored. From a theoretical understanding of the transition process, additional knowledge concerning support systems for graduate nurses is needed to help them become more secure in their profession. Nurse transitional programmes and their constituent components have not been extensively studied in a systematic manner to determine their efficacy. The aim of the present study is to describe the Clinical Nursing Introduction Program (CNIP) and present a study design in which the programme is used to support new graduate nurses' transition into the nursing profession.

\section{METHOD AND ANALYSIS}

This study places the CNIP in a broader context of sustainable working life by focusing on creating a safe and supportive environment for the nurses with the opportunity to progress into the profession. This study is based on the assumption that nurses leave their profession due to a sense of inadequacy associated with, for example, high levels of long-term stress. Therefore, it is important 
to create conditions to retain new graduate nurses. This programme illustrates a new approach not described earlier.

\section{Study design and setting}

This prospective longitudinal cohort study will be conducted among new graduate nurses employed for 14 months in the CNIP and will follow them for 2 years after the start of the programme. The study design consists of qualitative and quantitative methods in the collection and analysis of data. These will take place when the nurses start the CNIP (baseline), then after 1 and 2 years.

The CNIP was introduced in 2016 at a general hospital in southwest Sweden. Nurses with a maximum of 4 months of professional experience are offered employment within the CNIP. The purpose of the programme is to create a safe and supportive environment in which new graduate nurses are given the opportunity to progress into the profession through education, clinical supervision and critical reflection. Nurses at the start of their professional careers may need to practise their hands-on skills, as well as their theoretical knowledge. One way to strengthen new graduate nurses in their profession is to introduce PCC. At the study hospital, the healthcare professional works based on a person-centred approach; this means that it is equally important to be person centred when meeting with a patient as well as when meeting with colleagues.
The programme has two admissions each year at weeks 4 and 35 . The number of employed new graduate nurses in the CNIP varies between approximately 30 and 45 nurses at each admission. The CNIP consists of the following core components: employment and organisation, compulsory introduction week, placements in different clinical settings, education days and processoriented nursing supervision ( $\mathrm{POH}$ ) (table 1). The overall goal of nursing supervision is to support the development of professional identity, skills and ethics, and to ensure the quality of care for the patient. ${ }^{27} \mathrm{POH}$ in the CNIP is perceived as a central component and is highly valued in terms of the development of self-confidence in the professional role as a nurse. It is also an arena for exchanging experiences and sharing and acquiring new knowledge. The supervisors in the $\mathrm{POH}$ are registered nurses educated in Caring Science and Didactics Focused on Clinical Supervision (30 higher education credits). The supervisors themselves receive continuous supervision to develop their own professional development. The purpose of the education days in the CNIP is to improve patient safety, medical skills and competence based on experience-based learning and development. The new graduate nurses participate in continuous evaluations in connection with these education days. The CNIP organisation continues to develop the programme, making changes and improvements based on the evaluations.

Table 1 Core components of the Clinical Nursing Introduction Program (CNIP)

\section{Components Description}

Employment and The administrative organisation consists of a unit manager, an educational administrator and a programme organisation manager, each with a full-time position. The nurses are employed not by a specific clinic or unit; this means that they are employed by the CNIP as a registered nurse working under their own responsibility until further notice. Having completed the CNIP, the nurse is offered employment at a unit based on the nurse's own wishes and the needs of the care unit.

Compulsory During the compulsory introduction week, lectures are held and information provided about the CNIP as introduction week well as employment in the organisation at the hospital. The nurses perform practical training and review administrative systems, and they also receive some permissions. In addition, the nurses also practise cardiopulmonary resuscitation, and they are given a seminar in group dynamics.

Placements in The CNIP consists of two placements in different care units based on the nurse's wishes and the needs different clinical of the healthcare units. There is a specific introduction with daily support from a clinical supervisor for settings a minimum of 4 weeks at each care unit. In addition, the nurses also have an experienced nurse who monitors the clinical development; this can be compared with a mentorship. There is also an opportunity to auscultate at an additional care unit for 1 week per placement. The two placements provide professional competence and are performed at 6 and 8 months, respectively. The placement at 8 months runs over the summer period.

Education days Educational innovations during the CNIP expose new graduate nurses to a range of challenging environments. The incorporation of suitable levels of theoretical knowledge and practise of skills are required to support new graduate nurses for practice readiness. During the CNIP, the new graduate nurses receive 15 days of theoretical and practical education on current topics. Further, the nurses are trained to work with a person-centred approach.

$\begin{array}{ll}\begin{array}{l}\text { Process- } \\ \text { oriented nursing }\end{array} & \begin{array}{l}\mathrm{POH} \text { is a method in which self-experienced situations from healthcare are considered for examination } \\ \text { and processing, and the ethical patient perspective and nursing values constitute the framework for }\end{array} \\ \text { supervision (POH) } & \begin{array}{l}\text { reflection. The nurses participate in POH on } 8 \text { occasions. The group consists of } 6-8 \text { participants with the } \\ \text { same supervisor throughout the CNIP; furthermore, there is a confidentiality agreement in the group. The } \\ \text { atmosphere in the group is characterised by openness, responsiveness, curiosity and acceptance. The } \\ \text { group looks at patient-related and work-related situations. }\end{array}\end{array}$


Table 2 Study flowchart

\begin{tabular}{llll}
\hline Instruments & Baseline & $\begin{array}{l}\text { After 1 } \\
\text { year }\end{array}$ & $\begin{array}{l}\text { After 2 } \\
\text { years }\end{array}$ \\
\hline Sociodemographic data* & $\mathrm{X}$ & $\mathrm{X}$ & $\mathrm{X}$ \\
$\begin{array}{l}\text { Sense of Coherence-13 } \\
\text { Moral Sensitivity }\end{array}$ & $\mathrm{X}$ & $\mathrm{X}$ & $\mathrm{X}$ \\
$\begin{array}{l}\text { Questionnaire } \\
\text { Perceived Stress Scale-14 }\end{array}$ & $\mathrm{X}$ & $\mathrm{X}$ & $\mathrm{X}$ \\
Qualitative interviews & $\mathrm{X}$ & $\mathrm{X}$ & $\mathrm{X}$ \\
Reflective notes & $\mathrm{X}$ & $\mathrm{X}$ & $\mathrm{X}$ \\
\hline
\end{tabular}

*Including gender, age, marital status, previous work experience and also questions about food, sleep and exercise habit.

\section{Participants}

All new graduate nurses employed in the CNIP during the years 2019-2021 will be asked to participate in the study. During the first day of the introduction week, oral and written information is given to all nurses about the study, they are also given the opportunity to ask questions.

\section{Data collection}

The data collection started January 2019 and is expected to be completed in October 2023. Various methods of data collection, including questionnaires, qualitative interviews and reflective notes, will be used (table 2). The questionnaire will include questions about food, sleep, alcohol, exercise habits and sociodemographic data. We will register the number of new graduate nurses who are eligible to partake in the study. We will also register the number who starts and completes the CNIP, as well as the number of dropouts. In case of non-response at follow-up after 1 and 2 years, reminder will be sent out once. This is done in an attempt to maintain the participant in the study and increase the number of complete follow-ups. In addition, the follow-up after 1 and 2 years includes a question, addressed to those who have left the profession, about the reasons for leaving.

\section{Instruments}

\section{Sense of Coherence-13}

The Sense of Coherence-13 (SOC-13) will be used to measure the nurses' overall ability to manage difficult situations (coping strategies) ${ }^{28}{ }^{29}$ The instrument consists of 13 items on a 7-point Likert scale, ranging from 'very often' to 'very seldom or never', and evaluates perceived comprehensibility (five items), manageability (four items) and meaningfulness (four items). The minimum number of points that can be assigned to a question is 13 , and the maximum number is 91 . The higher the score, the stronger sense of coherence. The SOC-13 has been tested for validity and reliability in a number of studies and is translated into Swedish. ${ }^{29} 30$

\section{Moral Sensitivity Questionnaire}

The revised Moral Sensitivity Questionnaire (MSQ) will be used to assess the concepts of moral burden, moral strength and moral responsibility among the nurses. ${ }^{31} 32$ The original MSQ contained 30 items and was developed in psychiatric healthcare but has been modified and validated for use in other clinical settings. ${ }^{32}$ The current MSQ contains nine items with scales ranging from 'total disagreement' (1) to 'total agreement' (6) to assess the three concepts. Lützen $e t a l^{33}$ define moral sensitivity as an 'understanding of patients' vulnerable situation as well as an awareness of the moral implications of decisions that are made on their behalf' (p216). The definition supports the idea that moral sensitivity is a process that encompasses knowledge and skills related to the concepts of cognitive abilities, feelings, emotions and interpersonal interactions.

\section{Perceived Stress Scale-14}

The Perceived Stress Scale-14 (PSS-14) will be used in order to assess the degree to which people perceive their lives as stressful. High levels of stress are associated with poor self-reported health, elevated blood pressure, depression and susceptibility to infection. ${ }^{34}$ The PSS-14 has been tested for validity and reliability. ${ }^{34}$ Seven out of the 14 items of the PSS-14 are considered negative and the remaining seven as positive, representing perceived helplessness and self-efficacy, respectively. Each item was rated on a 5 -point Likert scale $(0=$ never to $4=$ very often $)$. Total scores for the PSS-14 range from 0 to 56. A higher score indicates greater stress.

\section{Qualitative interviews}

The scientific approach adopted in the qualitative part of this study is a Reflective Lifeworld Research approach (RLR). ${ }^{36}$ This will be used to describe and clarify nurses' lived experiences in a way that increases knowledge and understanding of the transition into the nursing profession. Qualitative interviews will be conducted in groups. Dahlberg $e t a l^{36}$ describe the interviews as a dialogue in which the informants' reflection on their own experiences is facilitated and encouraged through openness and flexibility. The orientation in the interviews will be on the phenomenon of interest 'the transition into the nursing profession'. The reflective process is encouraged with additional profound questions. Qualitative interviews in groups of six to eight nurses will be used at the start of the CNIP and after 1 and 2 years (table 2). The interviews will be held in separate rooms, (approximately $60 \mathrm{~min}$ ) and audio-recorded and transcribed verbatim. The interviews after 2 years may be conducted as individual telephone interviews for practical reasons.

\section{Reflective notes}

The transition process will be captured using 'reflective notes' (U Risling, personal communication, 9 July 2019). The nurses reflect, in writing, on their own actionsthe past, the present and the future-on a personal and professional level. These notes will be distributed to the participants at baseline and after 1 and 2 years. 


\section{Analysis of data}

Several statistical analyses will be performed. Statistical methods will be chosen and performed appropriately using the data. Descriptive statistics, using frequencies, percentages, median (quartiles) and mean value with ranges, will be used to provide a general description of the variables. The relationships between variables will be analysed using correlation procedures and multivariate statistics. To achieve an appropriate sample size for analysis with an $80 \%$ power and statistically significant level of a $\mathrm{p}<0.05$, we would need to assess 120 participants in the study. Clinically relevant change will be measured through estimates in questionnaires at baseline and the planned follow-ups at 1 and 2 years. We estimate that at least 25 new graduate nurses will accept to participate in the study at each admission. This would result in a total of approximately 150 nurses included in the study with a margin for dropouts at the follow-ups after 1 and 2 years. SPSS Statistics V.22 for Windows will be used for all analyses.

In the qualitative part of this study, the RLR approach will be used. ${ }^{36}$ RLR is characterised by a search for meaning and a focus on the phenomenon. By analysing and describing the essential meaning of the phenomenon, the actual phenomenon is understood in relation to its specific contexts. In this study, the context is 'Becoming and being a nurse: support in the transition process'. Data will be analysed for meanings with an open and reflective attitude and in a bridling manner. ${ }^{36}$ At the start, the transcripts from the interviews will be read with the object of getting a sense of 'the whole' and becoming familiar with the text. Questions such as: 'how do the data reflect the phenomenon' and 'what is the intrinsic meaning of the words' will be taken into consideration. After that, the text will be gradually divided into 'meaning units', that is, smaller parts containing meanings connected to the phenomenon. The meaning units identified in the text will be grouped into clusters, depending on their differences and similarities. These clusters highlight patterns of meaning, and as a result of this process an essence will be able to be described. The essence is the structure of the phenomenon. According to Dahlberg et $a l^{36}$ the aim of the analysis is to describe the essence of the phenomenon on an abstract level and its variations in more concrete constituents.

\section{Patient and public involvement}

Patients and/or the public were not involved in the initial development, or conduct, or reporting or dissemination plans of this research. The research design and objectives were developed by the investigators of this study, underwent review by academic advisors affiliated to the University of Skövde and a board of R\&D at Skaraborg Hospital.

\section{Ethics and dissemination}

The international guidelines for scientific research, as stated in the Declaration of Helsinki, will be considered regarding autonomy, integrity, beneficence, non-maleficence and justice. ${ }^{37}$ The study has been approved by the Regional Ethical Review Board in Gothenburg (Dnr 1056-18). Informed and written consent will be obtained from all participants in the study. They will also be informed that they can end their participation in the study at any time without explanation or consequence. No side-effects are expected. Study findings will be presented at national and international conferences and published in peer-reviewed journals.

\section{DISCUSSION AND RELEVANCE OF THE STUDY DESIGN}

This study will attempt to describe a programme that provides nurses with the necessary support during the transition process in the first years of the nursing profession. Nurses' progression into the profession during their first years of employment had previously been described from a transitional perspective ${ }^{25}$; our assessments will be made based on our understanding of the transition to professional practice, that is, before and after 'the confusing nowhere of in-betweenness', where change is inevitable and the individual must develop approaches to deal with this change one way or another. There are many education programmes for new graduate nurses with different names that are known to have an impact on the transition experience. The programmes are not described in detail, they have different lengths and content and are, therefore, difficult to assess. Specific programme objectives vary, although, broadly speaking, they all seek to reduce stress and anxiety, promote confidence and competence, and decrease nurse turnover. ${ }^{18}$ Therefore, it is important to describe the programme in detail, as in this study design, to evaluate the programme's validity. The CNIP has a unique profile based on a person-centred approach, ${ }^{24}$ consisting of five components: employment and organisation, a compulsory introduction week, placements in different clinical settings, education days and POH.

High turnover rates impact the quality of care, patient safety and organisational reputation. ${ }^{11}$ Individual and organisational factors that might contribute to new graduate nurses' experiences of stress have rarely been explored. ${ }^{38}$ The new graduate nurses at the study hospital are not employed by a specific clinic or unit; this means that they are employed by the CNIP. This kind of employment is unique and creates opportunities to gather experiences from different care contexts, allowing nurses to develop in their profession. The placements in different care units during the CNIP provide professional competence as well as an understanding of the organisation of the hospital. The objective of the education days is to link theory and practice through interprofessional collaboration. One method of addressing this gap is to use carefully linked, target-simulation experiences and practise of hands-on skills in a safe and supportive environment. Murray et $a l^{39}$ demonstrate the utility of models in understanding the learning experiences related to the 
transition towards safe, quality nursing practice and job satisfaction.

Learning is an embodied process of understanding that includes thoughts, experiences and feelings. Learning entails a change that occurs with the help of reflection and dialogue. ${ }^{40} 41$ One of the core components in the programme is $\mathrm{POH}$ which contains group reflection on the nurses' own work-related experience. It is also an arena for exchanging experiences and sharing and acquiring new knowledge. This corresponds with the model of supervision in nursing by Arvidsson $e t a l^{27}$ The overall goal is to increase self-confidence in one's professional role as a nurse, to improve skills and ethics, and to ensure the quality of care for the patient.

Nursing theories, models and the resulting framework provide a benchmark that nursing researchers can use to investigate and measure phenomena that may be affecting the safety and quality of nursing practice and job satisfaction. These phenomena may impact the future nursing workforce.$^{39}$ Key factors associated with effective transition programmes include mentoring and practical skills development. Furthermore, socialisation and facilitated learning opportunities with formal support should be made available throughout the transition into the profession. ${ }^{18} 42$

There are methodological considerations in this intervention design. To our knowledge, this study is the first to assess the reflective notes during the transition process through the first years of employment as a new graduate nurse. The nurses will reflect on their own actions, the past, the present and the future, on a personal and professional level. The importance of reflections has been emphasised in earlier studies. ${ }^{13}{ }^{15}$ However, the use of both qualitative and quantitative methodologies in the collection of data is a strength in this study design. This study design may increase the possibility of discovering findings and considers the diversity in scales used to measure stress, sense of coherence and moral sensitivity in new nurses. Labrague and McEnroe-Petitte ${ }^{38}$ studied job stress in new nurses during the transition period in an integrative review. They also highlight that inadequate sample size is common in several studies, and only a few studies have used a power analysis to estimate the required sample size. Failing to assure the correct sample size reduces the generalisability of the overall findings. In conclusion, the potential limitation of this study design includes the lack of an adequate full-term comparison group. The findings will inform the need for a future randomised scale study.

Contributors Study design—AJ, MB and AK. Data collection and analysis—AJ, MB and AK. Manuscript preparation—AJ, MB and AK. All authors read and approved the final manuscript.

Funding The authors have not declared a specific grant for this research from any funding agency in the public, commercial or not-for-profit sectors.

Competing interests None declared.

Patient and public involvement Patients and/or the public were not involved in the design, or conduct, or reporting, or dissemination plans of this research.
Patient consent for publication Not required.

Provenance and peer review Not commissioned; externally peer reviewed.

Open access This is an open access article distributed in accordance with the Creative Commons Attribution Non Commercial (CC BY-NC 4.0) license, which permits others to distribute, remix, adapt, build upon this work non-commercially, and license their derivative works on different terms, provided the original work is properly cited, appropriate credit is given, any changes made indicated, and the use is non-commercial. See: http://creativecommons.org/licenses/by-nc/4.0/.

ORCID iD

Anita Johansson http://orcid.org/0000-0001-9019-2402

\section{REFERENCES}

1 Frögéli E, Rudman A, Ljótsson B, et al. Preventing stress-related ill health among newly registered nurses by supporting engagement in proactive behaviors: development and feasibility testing of a behavior change intervention. Pilot Feasibility Stud 2018;4:28.

2 Herron EK. New graduate nurses' preparation for recognition and prevention of failure to rescue: a qualitative study. J Clin Nurs 2018;27:e390-401.

3 Ohlsson U. Vägen in i ett yrke: en studie av lärande och kunskapsutveckling hos nyutbildade sjuksköterskor (In Swedish). Career Paths - a study of newly qualified nurses' learning and knowledge development. Örebro universtitet 2009.

4 Parker V, Giles M, Lantry G, et al. New graduate nurses' experiences in their first year of practice. Nurse Educ Today 2014;34:150-6.

5 Halpin Y, Terry LM, Curzio J. A longitudinal, mixed methods investigation of newly qualified nurses' workplace stressors and stress experiences during transition. J Adv Nurs 2017;73:2577-86.

6 Duchscher JB. A process of becoming: the stages of new nursing graduate professional role transition. J Contin Educ Nurs 2008;39:441-50.

7 Spence Laschinger HK, Fida R. New nurses burnout and workplace wellbeing: the influence of authentic leadership and psychological capital. Burn Res 2014;1:19-28.

8 D'Ambra AM, Andrews DR, Incivility ADR. Incivility, retention and new graduate nurses: an integrated review of the literature. J Nurs Manag 2014;22:735-42

9 Rudman A, Gustavsson P, Hultell D. A prospective study of nurses' intentions to leave the profession during their first five years of practice in Sweden. Int J Nurs Stud 2014;51:612-24.

10 Hayes LJ, O'Brien-Pallas L, Duffield C, et al. Nurse turnover: a literature review - an update. Int J Nurs Stud 2012;49:887-905.

11 Ulrich B, Krozek C, Early S, et al. Improving retention, confidence, and competence of new graduate nurses: results from a 10-year longitudinal database. Nurs Econ 2010;28:363-76.

12 Benner P. Educating nurses: a call for radical transformation-how far have we come? J Nurs Educ 2012;51:183-4.

13 Benner PE. From novice to expert: excellence and power in clinical nursing practice. Upper Saddle River, NJ: Prentice-Hall, 2001.

14 Regan S, Wong C, Laschinger HK, et al. Starting out: qualitative perspectives of new graduate nurses and nurse leaders on transition to practice. J Nurs Manag 2017;25:246-55

15 Ten Hoeve Y, Kunnen S, Brouwer J, et al. The voice of nurses: novice nurses' first experiences in a clinical setting. A longitudinal diary study. J Clin Nurs 2018;27:e1612-26.

16 Blomberg K, Isaksson A-K, Allvin R, et al. Work stress among newly graduated nurses in relation to workplace and clinical group supervision. J Nurs Manag 2016;24:80-7.

17 Baumann A, Hunsberger M, Crea-Arsenio M, et al. Policy to practice: investment in transitioning new graduate nurses to the workplace. $J$ Nurs Manag 2018;26:373-81.

18 Adams JE, Gillman L. Developing an evidence-based transition program for graduate nurses. Contemp Nurse 2016;52:511-21.

19 Aggar C, Bloomfield J, Thomas TH, et al. Australia's first transition to professional practice in primary care program for graduate registered nurses: a pilot study. BMC Nurs 2017;16:14.

20 Rosenfeld P, Glassman K. The long-term effect of a nurse residency program, 2005-2012: analysis of former nurse residents. J Nurs Adm 2016;46:336-44.

21 The National Board of Health and Wellfare. Bättre resursutnyttjande I hälso- och sjukvården (in Swedish). better utilization of resources in health services. Stockholm: The National Board of Health and Wellfare, 2017.

22 Ekman I, Swedberg K, Taft C, et al. Person-centered care--ready for prime time. Eur J Cardiovasc Nurs 2011;10:248-51. 
23 McCance T, McCormack B, Dewing J. An exploration of personcentredness in practice. Online $J$ Issues Nurs 2011;16:1.

24 Ekman I. Personcentrering inom hälso- och sjukvård: från filosofi till praktik (Sve). person-centred care in health services. from philosophy to practice. Stockholm: Liber, 2014.

25 Meleis Al. Theoretical nursing: development and progress. Philadelphia: Wolters Kluwer, 2018.

26 Schumacher KL, Meleis Al. Transitions: a central concept in nursing. Image J Nurs Sch 1994;26:119-27.

27 Arvidsson B, Skärsäter I, Oijervall J, et al. Process-oriented group supervision implemented during nursing education: nurses conceptions 1 year after their nursing degree. J Nurs Manag 2008;16:868-75

28 Antonovsky A, Cederblad M, Elfstadius M. Hälsans mysterium (in Swedish). unraveling the mystery of health. Stockholm: Natur och kultur, 1991.

29 Antonovsky A. The structure and properties of the sense of coherence scale. Soc Sci Med 1993;36:725-33.

30 Langius A, Björvell $\mathrm{H}$. Coping ability and functional status in a Swedish population sample. Scand J Caring Sci 1993;7:3-10.

31 Lützén K, Evertzon M, Nordin C. Moral sensitivity in psychiatric practice. Nurs Ethics 1997;4:472-82.

32 Lützén K, Dahlqvist V, Eriksson S, et al. Developing the concept of moral sensitivity in health care practice. Nurs Ethics 2006;13:187-96.

33 Lützén K, Blom T, Ewalds-Kvist B, et al. Moral stress, moral climate and moral sensitivity among psychiatric professionals. Nurs Ethics 2010;17:213-24.
34 Cohen S, Kamarck T, Mermelstein R. A global measure of perceived stress. J Health Soc Behav 1983;24:385-96.

35 Andreou E, Alexopoulos EC, Lionis C, et al. Perceived stress scale: reliability and validity study in Greece. Int J Environ Res Public Health 2011;8:3287-98.

36 Dahlberg K, Dahlberg H, Nyström M. Reflective lifeworld research. Lund: Studentlitteratur, 2008.

37 World Medical Association. World Medical association Declaration of Helsinki. ethical principles for medical research involving human subjects, 2008. Available: http://www.wma.net/en/30publications/ 10policies/b3/index.html

38 Labrague LJ, McEnroe-Petitte DM. Job stress in new nurses during the transition period: an integrative review. Int Nurs Rev 2018;65:491-504.

39 Murray M, Sundin D, Cope V. Benner's model and Duchscher's theory: providing the framework for understanding new graduate nurses' transition to practice. Nurse Educ Pract 2019;34:199-203.

40 Berglund M. Att ta rodret i sitt liv: Lärande utmaningar vid långvarig sjukdom (In Swedish). Taking charge of one's life - challenges for learning in long-term illness. Linnaeus University Press 2011.

41 Ekebergh M. Lifeworld-based reflection and learning: a contribution to the reflective practice in nursing and nursing education. Reflective Practice 2007:8:331-43.

42 Erol R, Upton P, Upton D. Supporting completion of an online continuing professional development programme for newly qualified practitioners: a qualitative evaluation. Nurse Educ Today 2016;42:62-8. 